\title{
A case of erythroleukaemia in an eight year old boy
}

\author{
Shrey Rastogi ${ }^{1}$, Sumyra Khurshid Qadri ${ }^{2}$, * Pradeep Kumar Gupta ${ }^{3}$
}

Sri Lanka Journal of Child Health, 2017; 46(2): 187-189

DOI: http://dx.doi.org/10.4038/sljch.v46i2.8281

(Key words: Erythroleukaemia, M6 leukaemia, children)

\section{Introduction}

Erythroleukaemia was first recognized by Giovanni DiGuglielmo $^{1}$ from Italy in 1917 as a malignant condition and has been rarely reported in children ${ }^{2}$. It accounts for less than $1 \%$ of all childhood leukaemias and $2-7 \%$ of all acute myelogenous leukaemias ${ }^{3}$ with very few of them from India ${ }^{3-6}$. It is still referred to as acute Di Guglielmo syndrome and classified as M6 subtype of acute myelogenous leukaemia (AML) in French American British (FAB) classification. Its rarity has prompted us to report this case.

\section{Case report}

An eight year old boy presented with complaints of progressive pallor and fever off and on for one month. There was nothing contributory in the past or family history. Child was fairly nourished but had severe pallor. There was no lymphadenopathy, icterus, petechiae or bruises. No bony tenderness was present. Signs of congestive cardiac failure (raised jugular venous pressure and pedal oedema) were present. Abdomen was soft and liver as well as the spleen were not palpable. Respiratory, nervous and musculoskeletal systems were normal.

Haemoglobin was $3.3 \mathrm{~g} / \mathrm{dl}$ and the packed cell volume (PCV) was $11 \%$. The total leucocyte count was $3,200 / \mathrm{cu} \mathrm{mm}$ with $17 \%$ polymorphs, $63 \%$ lymphocytes and $20 \%$ blast cells. Peripheral blood smear had 23 nucleated red blood cells (RBC) per 100 leucocytes (Figure 1).

\footnotetext{
${ }^{1}$ Junior Resident, Department of Paediatrics, ${ }^{2}$ Assistant Professor, Department of Pathology, ${ }^{3}$ Professor of Paediatrics, SRMS IMS, Bareilly, India

*Correspondence: drgupta_jsr@rediffmail.com

(Received on 19 January 2016: Accepted after revision on 31 March 2016)

The authors declare that there are no conflicts of interest

Personal funding was used in formulating the article.

Open Access Article published under the Creative

Commons Attribution CC-BY (c) (P)
}

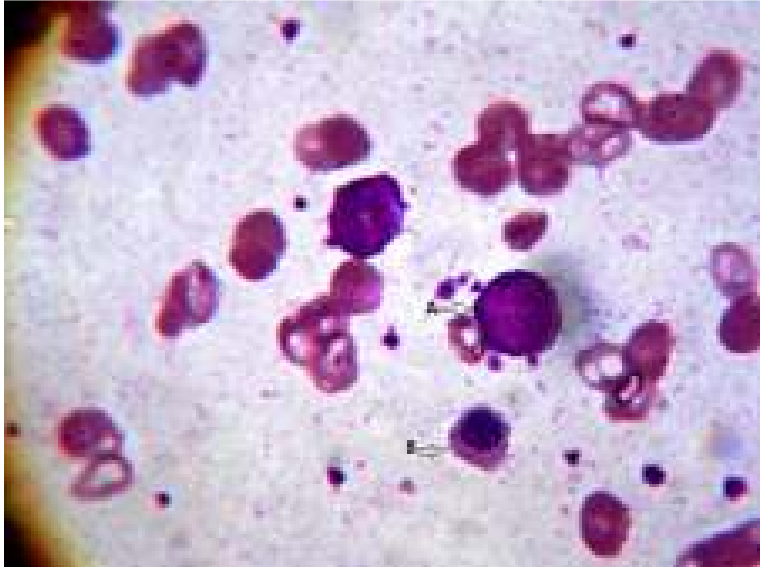

Figure 1: Peripheral blood smear. Leishman stain $(x$ 1000) showing erythroblast $(A)$ and nucleated red blood cell (B)

Reticulocyte count was $3 \%$ and the RBC count was $89,000 / \mathrm{cu} \mathrm{mm}$. The mean corpuscular volume (MCV) was 107.6fl, the mean corpuscular haemoglobin $(\mathrm{MCH}) 37 \mathrm{pg}$, the mean corpuscular hemoglobin concentration (MCHC) $31.4 \mathrm{~g} / \mathrm{dl}$ and the red cell distribution width (RDW) 17.4\%. The platelet count was $545,000 / \mathrm{cu} \mathrm{mm}$. The prothrombin time (PT) was 15 seconds (control 17 seconds), and augmented partial thromboplastin time (aPTT) 40 seconds (control 40 seconds). No haemoparasites were seen. Serum creatinine, liver function tests and serum proteins were all normal and so were the serum $\mathrm{B}_{12}$ and folate levels. Blood and urine cultures were sterile. Hepatitis B surface antigen (HBsAg) and antibodies to hepatitis $\mathrm{C}$ virus (anti $\mathrm{HCV}$ ) were negative. Chest $\mathrm{X}$ ray was normal.

Bone marrow aspirated from the posterior superior iliac spine showed erythroid hyperplasia, suppression of myeloid series and reversal of M: E ratio (3:1). Early immature cells with megaloblastic features were increased with $68 \%$ proerythroblasts. Megakaryocytes showed dysplastic features like hypolobation with presence of pawn ball megakaryocytes (Figure 2). 


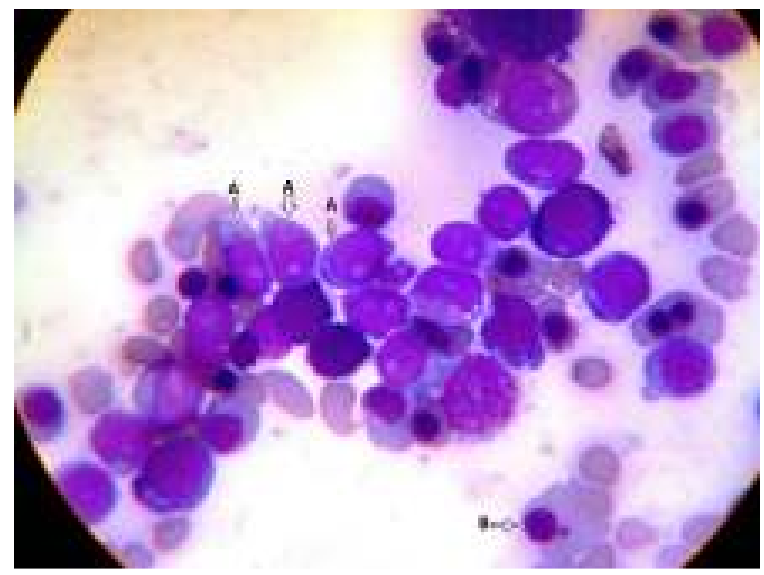

Figure 2: Bone marrow. Giemsa stain (x1000) showing proerythroblasts (A) and pawn ball megakaryocyte (B)

Periodic acid Schiff (PAS) staining was positive (Figure 3).

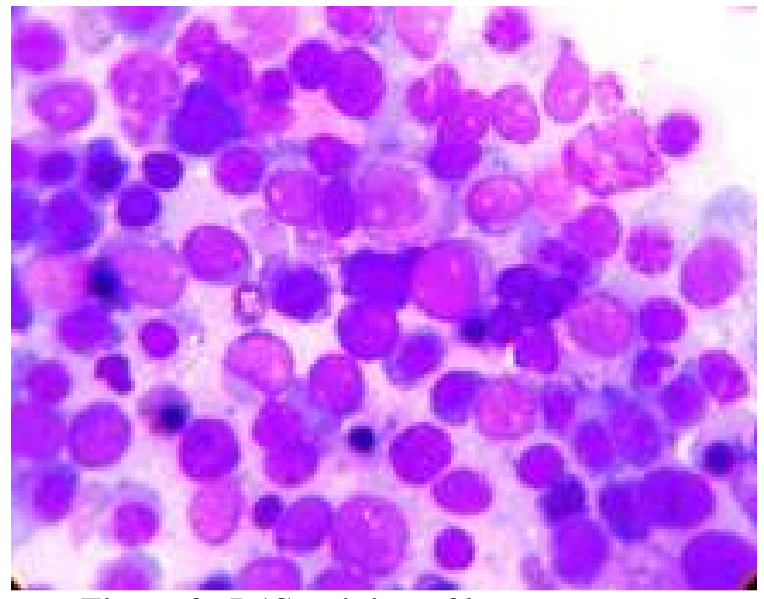

Figure 3: PAS staining of bone marrow

Flow-cytometry and genetic studies could not be done. On the basis of haematological and bone marrow features, a diagnosis of acute erythroleukaemia (AML-M6) was made. Treatment options were discussed and parents opted for supportive treatment only. Patient was discharged after packed $\mathrm{RBC}$ transfusions.

\section{Discussion}

Erythroleukaemia is a rare haematopoietic malignancy with predominant proliferation of panmyelotic precursors, erythroblasts as well as myeloblasts. It was first reported by Copelli in 1912 but recognized and described as a leukaemia by $\mathrm{Di}$ Guglielmo $^{1}$ in 1917. Only small numbers of cases, mostly as single case reports, have been reported in the paediatric population worldwide ${ }^{3}$. Even in adults there is paucity of data, there being only a single case in 10 years follow up from Tata Memorial Hospital, Mumbai ${ }^{2}$.

Three stages consisting of a primary erythroid phase (chronic erythraemic myelosis), a transient phase involving erythroid and myeloid precursors (erythroleukaemia) and a terminal pure myeloblastic phase (AML) have been described. Further, depending on the numbers of various blast cells M6 leukaemia has been classified into M6A, M6B and M6C. But, classification of EL depending on the numbers of types of blast cells is difficult as blasts are very dysplastic ${ }^{7}$. Common clinical presentations reported in children consist of male preponderance and marked pallor ${ }^{3,4}$. Hepatosplenomegaly and lymphadenopathy have been reported but are not common $^{3-6}$. Bleeding manifestations and rheumatic complaints are found to be more common in erythroleukaemia in comparison to other acute non lymphocytic leukaemia (ANLL) ${ }^{4}$. Pancytopenia as well as isolated thrombocytopenia have been commonly reported ${ }^{3,4}$. Batra et $a l^{4}$ reported thrombocytopenia in all of a series of four cases, the only multi-case paediatric series reported from India. Leucocytosis has been reported in a child ${ }^{6}$ as well as in adults ${ }^{7}$. It is important to differentiate erythroleukaemia from myelodysplastic syndrome, reactive erythroid hyperplasia sometimes following viral infections, other leukaemias and also from nutritional deficiency of vitamin $\mathrm{B}_{12}$ and folic acid ${ }^{6}$.

Megakaryocytes in erythroleukaemia are very often dysplastic with abnormalities of segmentation of the nucleus of or abnormalities of size (micromegakaryocytes $)^{8}$. Pawn ball megakaryocytes seen in our case are probably a feature of severe myelodysplasia

Management of AML (including M6 subtype) constitutes induction chemotherapy and postinduction/consolidation chemotherapy. Cytarabine is the most active agent and various regimens are designed around it. Induction therapy is "7 +3 " regimen: Cytarabine at $100 \mathrm{mg} / \mathrm{m}^{2} / \mathrm{d}$ intravenously (IV) by continuous infusion on days 1-7 plus an anthracycline (idarubicin $12 \mathrm{mg} / \mathrm{m}^{2}$ or daunorubicin $45-60 \mathrm{mg} / \mathrm{m}^{2}$ ) or anthracenedione (mitoxantrone 12 $\mathrm{mg} / \mathrm{m}^{2}$ ) ( IV) push on days1-38. Consolidation therapy includes 2 options. The high-dose ara-C (HiDAC) regimen includes cytarabine at $3 \mathrm{~g} / \mathrm{m}^{2} \mathrm{IV}$ q12h on days 1,3 , and 5 for 4 cycles. The " $5+2$ " regimen includes cytarabine at $100 \mathrm{mg} / \mathrm{m}^{2} / \mathrm{d}$ IV continuously infused on days 1-5 plus daunorubicin at $45 \mathrm{mg} / \mathrm{m}^{2} \mathrm{IV}$ on days 1 and 2 for a total of 2 cycles. A bone marrow biopsy should be performed 14 days after induction therapy to assess remission 
status. If persistent blasts are noted, a second course (with dose-reduced " $5+2$ " regimen) is recommended

Patients with acute erythroleukaemia have a poor prognosis often due to primary induction failure, relapse, and toxicity of chemotherapeutic agents. In a study of 91 patients with newly diagnosed erythroleukaemia, Santos et $\mathrm{al}^{9}$, after a multivariate analysis, concluded that erythroleukaemia is not an independent risk factor in disease-free and overall survival and standard AML prognostic factors should guide treatment. Median disease-free survival reported was 32 weeks and median period of overall survival was 36 weeks. Others have reported a median survival from 3.5 to 77 months ${ }^{8}$.

In our case, the duration of illness was one month which is similar to 4 of the seven paediatric $\operatorname{cases}^{3,4,6}$ from India while in 3 cases it was more than 6 months $^{3,5}$. Our case had an unusual feature of thrombocytosis in spite of depressed red as well as white blood cell lines. Thrombocytosis has been reported in acute lymphocytic leukaemia (ALL) and chronic granulocytic leukaemia (CGL), but we could not find any report of thrombocytosis in erythroleukaemia. A low leucocyte count with proerythroblast predominance in the bone marrow as well as peripheral blood smear suggests that case was probably still in Stage I only.

\section{References}

1. Di Guglielmo G. "Richerche di ematologia. I. Un caso di eritroleucemia. Megacariociti in circolo e loro funzione piastrinopoietico". Folia Medica (Pavia) 1917; 13: 386.

2. Attill SVS, Dadhich HK, Jakob LA, G Anupama, Bapsy PP, Devi L, et al. A retrospective study of clinicohaematological and cytogenetic profile of erythroleukaemia from South India. Turkish Journal of Hematology 2006; 23: 158-63.
3. Batra VV, Karan AS, Saxena R. Erythroleukaemia: a clinico-haematological review of four cases. Indian Pediatrics 2004; 41(6): 587-90.

PMid: 15235164

4. Gupta PC, Tayal A, Narayan S, Logani KB, Aneja S. Erythroleukaemia. Indian Pediatrics 1991; 28: 422-5.

PMid: 1752664

5. Gupta PK, Mishra PK, Srivastava KL, Kushwaha MRS. Erythroleukaemia: a case report. Indian Journal of Cancer Chemotherapy 1981; 3: 71-2.

6. Sharma A, Buxi G, Walia R, Yadav RB, Sharma S. Childhood acute erythroleukaemia diagnosis by flow cytometry. Indian Journal of Pathology \& Microbiology 2011; 54: 173-5. http://dx.doi.org/10.4103/0377-4929.77395 PMid: 21393910

7. Rasool J, Geelani S, Khurshid Y, Lone MS, Shaban M. Pure erythroleukaemia (variant acute myeloid leukemia-VAML- (M6) with deletion of chromosome 20, mainly presenting as late erythroblasts, a unique case report with review of literature. Indian Journal of Hematology \& Blood Transfusion 2014; 30: 34-7. http://dx.doi.org/10.1007/s12288-012-01809

PMid: 24554819 PMCid: PMC3921337

8. Park S, Picard F, Dreyfus F Erythroleukaemia a need for new definition. Leukemia 2002; 16:1399-401. http://dx.doi.org/10.1038/sj.leu.2402549 PMid: 12145675

9. Santos FP, Faderl S, Garcia-Manero G, Koller C, Beran M, O'Brien S, et al. Adult acute erythroleukaemia: an analysis of 91 patients treated at a single institution. Leukemia. 2009; 23:2275-80. http://dx.doi.org/10.1038/leu.2009.181 PMid: 19741728 PMCid: PMC4217206 